\title{
Promising directions of increasing the properties of steel
}

\author{
A. I. Zaitsev ${ }^{1}$, A. V. Koldaev ${ }^{1}$, N. A. Arutyunyan ${ }^{2}$ \\ ${ }^{1}$ Bardin Central Research Institute of Ferrous Metallurgy, \\ Radio str., 23/9, build.2, Moscow, 105005, Russia \\ ${ }^{2}$ Department of Chemistry, Lomonosov Moscow State \\ University, Leninskie Gory 1-3, GSP-1, Moscow, 119991, Russia \\ aizaitsev1@yandex.ru, koldaevanton@gmail.com, naarutyunyan@gmail.com
}

PACS 64.30.Ef

DOI 10.17586/2220-8054-2018-9-4-500-506

\begin{abstract}
The study of regularities of the formation and evolution of nonmetallic inclusions and phase precipitates in modern structural steels has been carried out. It has been shown that the formation of several types of complex nonmetallic inclusions results in a substantial increase in the complex of steel properties and neutralizing the negative influence of impurities while a reduction in costs. An even more significant improvement in the properties of steel can be achieved by controlling the characteristics of carbide, carbonitride, and other types of phase precipitates. Herewith, ferritic steels are the most promising. The previously unreachable complex of indicators of difficult to combine service properties of these steels has been achieved by the formation of a homogeneous fine-dispersed microstructure and a volumetric system of primarily interphase precipitates. Based on established principles, effective technologies for the production of a wide range of various types of steels have been developed.
\end{abstract}

Keywords: structural steels, nonmetallic inclusions of complex composition, nanoscale phase precipitates, interphase precipitates, structure, service properties, production technology.

Received: 31 May 2018

\section{Introduction}

At present, steels find an ever expanding sphere of application and are becoming increasingly unique and high-technology materials. This is reflected in the rapid growth in requirements for the composition, nonmetallic inclusions, macro- and microstructural state, a complex of indicators of the level and stability of their technological, service properties, and qualitative characteristics when the legislative striving to reduce the material and energy costs of production, the intensification of the end-to-end technological process and work equipment takes place. In particular, over the last $5-10$ years, the indicators of most properties of steels have increased several times, and the task for developing a wide range of new types is to achieve extremely high following parameters: strength (up to $2000-2200 \mathrm{MPa}$ ), plasticity (elongation to $55-60 \%$ ), cold resistance $\left(\mathrm{KCV}_{-60^{\circ} \mathrm{C}}\right.$ up to $300-400 \mathrm{~J} / \mathrm{cm}^{2}$ ), stamping, corrosion resistance, qualitative characteristics (the content of nonmetallic inclusions is not more than 1.0 - 1.5 ball according to GOST 1778-70, some unfavorable types - not more than 2 inclusion/ $/ \mathrm{mm}^{2}$ regardless of their size, sulfur - no more than $0.001 \%$, the number of surface defects - no more than $1-2$ per ton of rolled metal) [1]. An important fact is that in most cases it is necessary to ensure high values of not only one of these parameters, but of the whole complex, as a rule, of difficult to combine properties, for example, strength and plasticity; stamping, cold resistance, fatigue, and corrosion resistance, etc.

The solution of this problem lies only in the way of developing fundamentally new scientific, technical methods of research and solutions. According to the results of a large volume of studies [1-3], they are primarily related to the development and use of adequate predicting methods and effective technological strategies of controlling a number of characteristics. They include type, composition, quantity, size, morphology, and distribution by volume of metal of nonmetallic inclusions, phase precipitates, forms of presence of impurities controlling the resulting structural state and complex properties of steel. Moreover, in order to achieve fundamental progress in the direction under consideration, it is necessary to take an adequate account of the kinetics of processes occurring during metal treatment, deviations from equilibrium, and the possibility of forming nanoscale and complex objects of the structural state of steel.

\section{Regularities of changes in the characteristics of nonmetallic inclusions in modern steels}

As a result of the rapid development of metallurgical technology, the use of new materials, technological methods, the intensification of treatment processes, and the production of steel, the characteristics of nonmetallic inclusions and other elements of the structure present in the metal have fundamentally changed. First of all, 
the variety of types of existing nonmetallic inclusions (precipitates) has significantly increased. In many cases they have a complex chemical and phase composition, which regularly changes during the processing of steel. In particular, the need to reduce the sulfur content to low values (often less than $0.001 \%$ ) to increase the cold resistance, viscosity, and resistance to hydrogen sulfide stress cracking have required a reduction in the dissolved oxygen content in the metal to $0.0005-0.0008 \%$, and $\mathrm{FeO}$ in the slag - to $0.5-1 \%$. As a result, the deoxidizing interaction with lining and slag becomes possible, and the formation of inclusions based on alumomagnesium spinel and other $\mathrm{MgO}-\mathrm{Al}_{2} \mathrm{O}_{3}, \mathrm{MgO}-\mathrm{Al}_{2} \mathrm{O}_{3}-\mathrm{CaO}$ compositions takes place [4]. This type of inclusions often dominates in modern steels, despite the fact that less than 10 years ago they were practically absent.

According to the results of the most recent detailed studies [5,6], it has been established that under certain modes of ladle treatment and continuous casting of modern structural steels oxide inclusions are formed based on $\mathrm{SiO}_{2}-\mathrm{Al}_{2} \mathrm{O}_{3}, \mathrm{SiO}_{2}-\mathrm{Al}_{2} \mathrm{O}_{3}-\mathrm{CaO}, \mathrm{MnO}-\mathrm{SiO}_{2}$, and $\mathrm{SiO}_{2}-\mathrm{Al}_{2} \mathrm{O}_{3}-\mathrm{MnO}$ compositions and others, which in many respects determine the resulting structural state and complex of metal properties. Among them are vitreous inclusions. The presence of vitreous silicate based inclusions essentially improves the macro- and microstructure of the metal of continuously cast billets (CCB), inhibits the development of liquation processes. Rolled products made

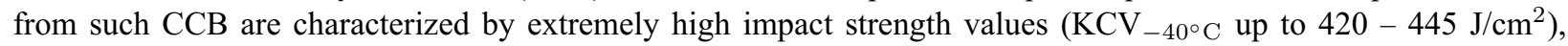
resistance to hydrogen cracking, and a number of other service properties. The presence of this type of nonmetallic inclusions in low-alloyed aluminum deoxidized structural steels is a rather unexpected fact, both from the theoretical and from the practical point of view. It became possible only due to the addition of large masses of manganese and silicon containing ferroalloys in the final stages of ladle treatment of steel and the presence of significant kinetic limitations for the transformation of silicate inclusions into more stable aluminate inclusions. Thus, kinetic reasons led to a significant expansion of the types of existing inclusions in modern steels.

The change in the size of nonmetallic inclusions is also significant. The intensification of metal melt treatment processes has created favorable conditions for nucleation but not for the growth of inclusions (precipitates) already present. Thus, it promotes the regular decrease in their size, which, often, is on the order of nanometers in magnitude. As a result, when modern metallurgical technologies are implemented, the formation and evolution of nanoscale objects in the steels takes place already at the stage of processing the metallic melt [7]. There are all the prerequisites for using them instead of or in addition to phase precipitates and structural components formed due to the use of costly alloying and microalloying components, which play a key role in achieving the structural state and high complex of steel properties $[1,4,6,7]$.

A second, no less important consequence of intensification of metal treatment processes is the creation of favorable conditions not for the independent nucleation and growth of phase precipitates, but for the deposition of phases on the surface of already present particles. This leads to the formation of a large variety of inclusions (precipitates) of complex composition. In particular, in Ti microalloyed structural steels complex inclusions, which consist of titanium nitride with corundum, with calcium and manganese sulfides, and alumomagnesium spinel, were detected [1]. In a wide range of structural steels, the formation of calcium and manganese sulfides on the surface of inclusions based on alumomagnesium spinel and calcium aluminates was registered [4,8]. During the thermo-deformation treatment of metal, cementite deposition on the surface of complex and a number of simpler inclusions (precipitates) is possible. To date, there are no adequate physico-chemical, kinetic, and structuralgeometric principles and methods for predicting the conditions of formation and the composition of complex inclusions [1].

\section{Specifics of the influence of nonmetallic inclusions on the properties of modern steels}

Depending on their characteristics, the inclusions present have significantly different effects on the structural state and properties of the steel. For example, the large sized titanium nitride precipitates (more than 8 - 10 microns) facilitate the initiation of metal defects, reducing the cold resistance and resistance against various types of corrosion-mechanical destruction of rolled metal [9]. The formation of complex TiN precipitates on corundum of intermediate sizes (as a rule up to $3-4 \mu \mathrm{m}$ ) inhibits the formation of its independent coarse precipitates. In addition, their ability to restrain the growth of austenitic grain when heating blanks for rolling, austenization, welding, and recrystallization during rolling is important [4]. Inclusions based on alumomagnesium spinel and a number of other oxide compositions do not adversely affect corrosion resistance and service properties; on the contrary, they can restrain grain growth during austenitization and recrystallization of steel that is associated with a certain positive effect. The deposition of sulfides of calcium and, mainly, manganese on their surface gives the resulting complex oxide-sulfide inclusions an unfavorable ability to catastrophically accelerate the local corrosion of steel [10].

In the presence of additional cementite (Fig. 1) and other carbide phase deposition, which have higher strength and hardness in comparison with the metal matrix, on the surface of sulfide, oxide-sulfide, and other complex 
inclusions, the formed complex precipitations can play the role of a strengthening phase. They can lead to a multiple (more than 2-3-fold) increase in the strength properties of steel while maintaining high plasticity [11]. Thus, the presented results indicate a fundamental change in the nature of the effect of nonmetallic inclusions on the properties of the metal, depending on the parameters of their formation and evolution during the processing of steel. The presented information reflects the regularities of influence for only a small number of possible types of complex nonmetallic inclusions (precipitates) on the quality and properties of steel. This stipulates the necessity of creating a database and adequate physico-chemical and kinetic methods for predicting the formation and evolution of complex nonmetallic inclusions (precipitates) at all stages of steel production (processing) that will be the basis for development of effective techniques for obtaining an unattainable complex of properties and qualitative indicators of metal. This approach opens up wide opportunities for the creation of new high-quality steels while a significant reduction in material and energy production costs, since the composition of obtained complex inclusions consists of widely distributed elements, which are usually present in steel and slag, e.g. Ca, $\mathrm{Al}, \mathrm{Mn}, \mathrm{Si}, \mathrm{C}$, and, even, the so-called harmful impurities - O, N, S [3,4,12]. No less significant effect is achieved due to the neutralization of the impurities' negative influence on technological and service properties of steel, and expansion of raw materials base.

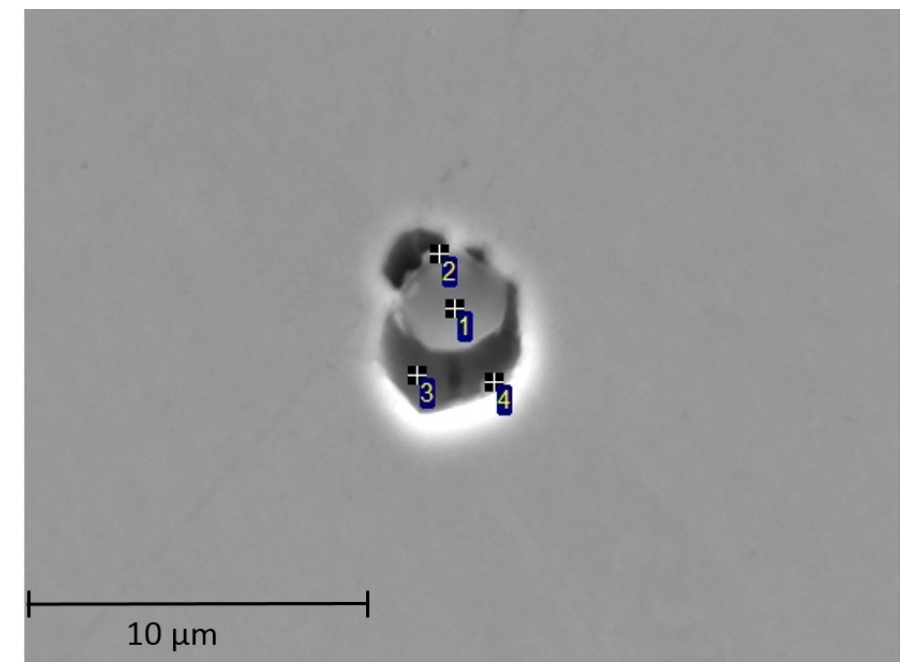

FIG. 1. Cementite precipitation on the surface of complex MnS and alumomagnesium spinel inclusion: 1 - MnS, 2 - alumomagnesium spinel, 3,4 - cementite

\section{Promising directions of using phase precipitates for the principal enhancement of the complex of properties of modern steels}

A greatly more significant increase in the complex properties of structural steels can be achieved by controlling the characteristics of carbide, carbonitride, and other types of phase precipitates, including complex composition, and structural constituents, formed during the treatment of solid metal. Nevertheless, in spite of the fundamental importance of this problem, as a rule, a number of traditional extremely simplistic approaches are used, which to some extent differ, depending on the requirements and the type of produced and developed steels. This can be clearly illustrated by the methods of formation and enhancement of the properties of high-strength automobile body sheet steels. It is one of the most important directions for the development of domestic and world science and technology. Up to the present time, low-alloyed high-strength steels with a yield strength of up to $600-$ $700 \mathrm{MPa}$ occupy the leading position (production and consumption volume is more than ten times higher than the total volume for all other high-strength automobile body sheet steels) [12]. The principle of their construction is based on the implementation of traditional strengthening mechanisms (grain-boundary, solid-solution, dispersion hardening) that leads to a catastrophic decrease in ductility and other service properties of steel. In view of this problem, progressive automobile body sheet steels have been developed, which include two-phase ferriticmartensitic, and multiphase steels, and steels with ductility induced by phase transformation (TRIP and TWIP steel) [13]. Their necessary strength is provided by the presence of a certain content of hard structural constituents (martensite, bainite, etc.) in the ferrite matrix.

To enhance the strength of progressive automobile body sheet steels, it is necessary to increase the content of these hard structural constituents that leads to a catastrophic decrease in stamping, corrosion resistance, and a 
number of other properties. These steels are characterized by a large difference in hardness between the ferrite matrix (soft polygonal ferrite) and hard structural components (martensite, bainite, etc.). Therefore, it is not possible to achieve high values for the hole expansion ratio, which is associated with the formation of cavities at the interface between the ferrite matrix and the hard structural components during stamping [14]. As a result, in spite of satisfactory values of the relative elongation, steels are characterized by an extremely low or even complete lack of stamping. In addition, the presence of distinct microstructure heterogeneity leads to a significant decrease in the corrosion resistance of the steel, makes it difficult to apply protective coatings, weldability, etc.

The currently used approaches for increasing the strength of traditional high-strength low-alloyed automobile body sheet steels up to $800-900 \mathrm{MPa}$ are mainly aimed at obtaining a bainite microstructure [15]. It is assumed that carbide and carbonitride precipitates play, in the main, only a secondary role in increasing the indicators of its dispersion. This leads to a sharp decrease in ductility and other functional properties of steel. It is important, that by obtaining a homogeneous bainitic microstructure, the hole expansion ratio remains satisfactory while a sharp decrease in the ductility of the steel. Thus, for all common types of automobile body sheet steels, especially of high strength grades, the problem of simultaneously obtaining difficult to combine high indicators of plasticity, stamping, corrosion resistance, operational reliability, and other service properties is not solved.

The most promising direction for the solution of the formulated task is the creation of new steels with a homogeneous plastic ferrite matrix strengthened by a system of thermally stable (up to $700{ }^{\circ} \mathrm{C}$ ) system of nanoscale, especially interphase (formed during the fcc-bcc phase transformation of steel), precipitates and refinement of ferrite grains up to $2-3 \mu \mathrm{m}$. Because of the formulated principles, nanostructured steels such as NANOHITEN [16] have been created to date and JFE Steel (Japan) and China have produced industrial batches of hot-rolled products. Ferrite microstructure of steel has a high strength up to $700-800 \mathrm{MPa}$, yet, at the same time, provides high plasticity (relative elongation up to $20-25 \%$ ), stamping (hole expansion ratio about $100 \%$ ), stiffness, durability, and fatigue and corrosion resistance.

The steel has an extremely economical composition, (mass.\%): $\mathrm{C}-0.04-0.06, \mathrm{Mn}-$ up to $1.5, \mathrm{Ti}+\mathrm{Mo}-\mathrm{up}$ to 0.3 and simple production technology with high temperatures of finishing of rolling $\left(900-920{ }^{\circ} \mathrm{C}\right)$ and coiling $\left(650{ }^{\circ} \mathrm{C}\right)$. The strengthening of the steel takes place, to a large extent, due to the formation of nanoscale complex (Ti, Mo)C carbide precipitates after coiling. This greatly simplifies the production of rolled products and allows it to be produced in thicknesses of $1.8 \mathrm{~mm}$. Due to the absence of silicon in the composition, the rolled products are well suited to hot-dip galvanizing and have shown excellent results in the manufacture of chassis, frame, and strength members of the automobile [17].

In the following years, the hot-rolled ferritic steels of the XPF type of XPF650, XPF800 and XPF1000 strength grades have been developed and produced on Tata Steel. They have various microalloying systems, including $\mathrm{V}, \mathrm{Nb}$, $\mathrm{Ni}, \mathrm{Mo}$, and, in some cases, B [18,19], which differ from NANOHITEN. Hot-rolled steels of the XPF type have a unique single-phase ferrite microstructure strengthened by nanoscale precipitates and excellent characteristics, which allow manufacturers to produce parts that are 15 percent lighter than those, made from similar brands of other types, including progressive automobile body sheet steels, in particular HR CP800.

However, despite the excellent array of properties, the widespread development and expansion of such steels has not occurred to date. The possibility and principles of further increase and the limiting values of their strength are not clearly substantiated. This is mainly due to a number of unresolved fundamentally important scientific problems. First of all, there is a lack of clear scientific ideas about the regularities in the formation of a thermally stable system of nanoscale interphase precipitates playing a key role in providing an array of properties of steel. Few investigations have been devoted to a theoretical investigation of this problem [20-25]. On the other hand, the results of experimental studies [26-28] indicate the possibility of a significant increase in the indicators of strength, plasticity, and stamping of steel of this type while using an extremely economical alloying system. In addition, the problem of the possible superposition of phase precipitates of various types (formed in austenite, ferrite, and during fcc-bcc transformation) for the principal enhancement of the complex of properties of steel, including the difficult to combine characteristics, has not yet been practically studied. Nevertheless, the results of the experimental and theoretical estimates carried out testify to the possibility of implementing additional mechanisms for improving the complex properties of rolled products [2], especially when the sizes of various types of phase precipitates decrease.

However, this is currently restrained by the lack of accurate information about the regularities of the influence of the nonmetallic inclusion characteristics and phase precipitates on the implementation of various mechanisms of the formation of the structural state, mechanical and other service properties of structural steels, and adequate predictive methods and effective techniques for controlling these characteristics. It connects with a number of objective difficulties due to the complexity and interconnectedness of modern metal treatment processes, which take place under conditions far from equilibrium. The determination of their direction and degree of implementation with the required accuracy is, in many cases, hindered or even impossible. As a result, the choice of the composition and 
parameters of steel treatment, in many ways is done by the method of trial and error using extremely simplified empirical relationships. Only recently, methods of thermodynamic modeling and calculation of steel treatment processes have been intensively developed $[4,14,29]$. Herewith, assuming the achievement of global or local equilibrium without taking into account deformation, only the total content of the formed phase is calculated. On the other hand, it is well known that the nature of the effect of phase precipitates on the structural state and properties of steel depends to a large extent on their characteristics. In addition, as shown by the results of the most recent detailed studies, even in the presence of deformation, the formation of carbide, carbonitride, and other phase precipitates has large kinetic limitations [30] and requires a considerable period of time, often much longer than the duration of hot rolling, for its realization. Thus, the actual task in the development of a new generation of steels is to create a fundamental database on the dependence of the characteristics of phase precipitates on the parameters of steel treatment, and the regularities governing their influence on the resulting structural state and properties of the metal.

In particular, the results of detailed experimental studies have shown that the fraction of molybdenum in the complex carbide (Ti,Mo)C in Ti, Mo microalloyed ferritic steels is insignificant and reaches a maximum value of $\mathrm{Ti}_{0.43} \mathrm{Mo}_{0.08} \mathrm{C}_{0.49}$ at the temperature of the $\gamma \rightarrow \alpha$ transformation of steel. Therefore, the formed interphase precipitates have a composition close to $\mathrm{TiC}$, and the role of molybdenum is in many respects associated with a decrease in the rate of phase transformation of the steel. The main contributions to the formation of strength properties are associated with obtaining a finely dispersed ferrite structure and dispersed carbide precipitates. The refinement of ferrite grain during the phase transformation is mainly influenced by carbide precipitates formed in austenite. Strengthening by nanoscale, especially interphase precipitates, is more effective with larger number and smaller sizes. It takes place when sizes of precipitates and distances between the resulting layers of precipitates are small (Fig. 2). All other conditions being equal, the amount of formed interphase precipitates increases with an increase in the content of phase-forming elements in the solid solution, the temperatures of finishing of rolling and coiling, as well as the rate of formation of small precipitates $(1-2 \mathrm{~nm})$ and phase transformation. On the other hand, an increase in the temperature of finishing of rolling and, as a result, the content of the phase-forming elements in the solid solution, can lead to a decrease in the amount of precipitates, which form in the austenite, and the dispersion of the resulting ferrite microstructure, reducing the contribution of this factor to the strength characteristics. The presented circumstances indicate that the numerical values of the metal treatment parameters and various types of phase precipitates must be coordinated. It will ensure the obtaining the maximum indicators of the complex of properties. In particular, this can be illustrated by a simple example. At close values of the treatment parameters and the content of the components in Ti, Mo, microalloyed ferritic steels increasing in the Ti concentration from 0.096 to 0.12 mass\% led to an increase in the strength of the steel from 780 to almost $900 \mathrm{MPa}$. Under such conditions, the amount of austenite and interphase precipitations, which control the various strengthening mechanisms, grew practically proportionally. In particular, the average size of the interphase precipitates was $1-2 \mathrm{~nm}$, the average distance between the layers is $5-8 \mathrm{~nm}$ (Fig. 2) [28].

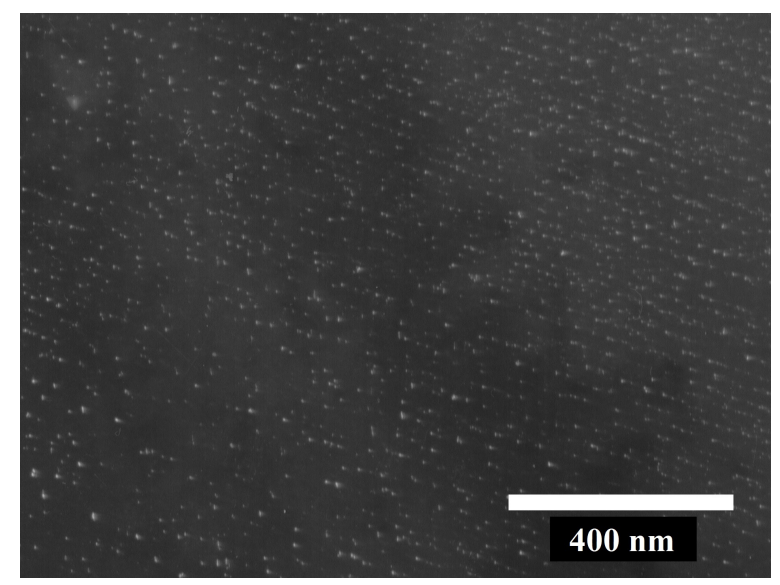

FIG. 2. Appearance of interphase carbide precipitates in Ti, Mo microalloyed ferritic steel, TEM [28] 


\section{Conclusion}

The presented example demonstrates that only an adequate accounting of the influence of all the processing and treatment parameters of the metal, as well as of all the features of various mechanisms for the formation of the structural state and properties, allows us to increase the parameters of the complex of difficult to combine characteristics of steel essentially. The high efficiency of the formulated approach has now been confirmed in the development of a variety of new technical and technological solutions, technologies, and steel grades (see, for example, [28]). In particular, a significant increase in the homogeneity of the composition, structure, and properties of the metal has been achieved due to the formation of favorable silicate, complex, and other types of inclusions / precipitates. Efficient technologies have been developed for production of a wide range of structural, tube, automobile body sheet, clad, and other types of mass high-quality steels with a fundamentally improved complex of difficult to combine strengths, ductility, cold resistance, corrosion resistance, operational reliability, weldability, and other properties for transport, machine building, fuel and energy complex. New types of steels have been created. Among them, ferritic steels, which are hardened by thermally stable systems of nanoscale precipitates, and ferrite-cementite steels that are resistant to destruction in active carbon and hydrogen-containing gas media. At the same time, a significant reduction in costs and expansion of the raw material base has been achieved.

\section{Acknowledgement}

This research was supported by the grant of the Russian Research Foundation (Project No. 18-19-00639) and was performed at the Bardin Central Research Institute of Ferrous Metallurgy.

\section{References}

[1] Zaitsev A.I. Prospective directions for development of metallurgy and materials science of steel. Pure Appl. Chem., 2017, 89(10), P. 1553-1565.

[2] Zaitsev A.I., Kosyrev K.L., Rodionova I.G. Modern trends of development of metallurgical technology for achievement of a high complex of service properties and qualitative indicators of steel. Probl. Chern. Met. Materialoved, 2012, 3, P. 5-13.

[3] Shakhpazov E.Kh., Zaitsev A.I., Rodionova I.G., Semernin G.V. Key trends in the development of a metallurgical technology to meet the growing steel quality requirements. Russ. Metall., 2011, 2011(12), P. 1162-1170.

[4] Zaitsev A.I., Kraposhin V.S., Rodionova I.G., Semernin G.V., Talis A.S. Complex nonmetallic inclusions and steel properties. Metallurgizdat, Moscow, 2015, 276 p.

[5] Zaitsev A.I., Rodionova I.G., Baklanova O.N., Kryukova A.I., Udod K.A., Mishnev P.A., Mitrofanov A.V. Nonmetallic inclusions and promising principles for Improving the set of properties and quality characteristics of steel. Metallurgist, 2015, 58(11), P. 983-991.

[6] Zaitsev A.I., Stepanov A.B., Karamysheva N.A., Rodionova I.G. Advancement of the properties of structural steels by creating an optimum form of existence of impurities and nonmetallic inclusions. Met. Sci. Heat Treat., 2016, 57(9), P. 531-538.

[7] Shakhpazov E.Kh., Zaitsev A.I., Rodionova I.G., Shaposhnikov N.G. Nanotechnologies for the production of mass high-quality steels based on the management of nanosized precipitates of nonmetallic excess phases. Probl. Chern. Met. Materialoved., 2008,4 , P. 112-122.

[8] Zaitsev A.I., Rodionova I.G., Semernin G.V., Shaposhnikov N.G., Kazankov A.Yu. New types of unfavorable nonmetallic inclusions based on $\mathrm{MgO}-\mathrm{Al}_{2} \mathrm{O}_{3}$ and metallurgical factors governing their content in metal. Part 1 . Reasons and mechanisms for formation in steel of nonmetallic inclusions based on alumina magnesia spinel. Metallurgist, 2011, 55(1-2), P. 107-115.

[9] Zaitsev A.I., Rodionova I.G., Baklanova O.N., Udod K.A., Grishin A.V., Esiev T.S., Ryahovskih I.V., Kohtev S.A., Lutsenko A.N., Nemtinov A.A., Mitrofanov A.V. Investigation of the influence of metallurgical factors on the resistance of modern tube steels against corrosion cracking. Probl. Chern. Met. Materialoved., 2013, 1, P. 54-69.

[10] Rodionova I.G., Zaitsev A.I., Baklanova O.N., Golovanov A.V., Endel N.I., Shapovalov E.T., Semernin G.V. Modern approaches to improve the corrosion resistance and operational reliability of steels for oilfield pipelines. Metallurgizdat, Moscow, 2012, $172 \mathrm{p}$.

[11] Zaitsev A.I., Rodionova I.G., Shaposhnikov N.G., Mogutnov B.M., Dunaev S.F., Mishnev P.A., Adigamov R.R. Development of scientific foundations for efficient technologies for the production of cold-rolled high-strength low-alloyed steels by controlling the type, quantity and morphology of precipitations of nonmetallic excess phases. Probl. Chern. Met. Materialoved., 2012, 1, P. 75-85.

[12] Zaitsev A.I., Rodionova I.G., Yashchuk S.V., Mishnev P.A., Adigamov R.R., Bykova Yu.S., Efimova T.M. Development of scientific and technological fundamentals of production of automobile body sheet steels. Chernaya Metllurgiya, 2013, 3, P. 89-109.

[13] Fonstein N. Advanced high strength sheet steels: physical metallurgy, design, processing and properties. Springer International Publishing Switzerland, 2015, 396 p.

[14] Frisk K., Borggren U. Precipitation in microalloyed steel by model alloy experiment and thermodynamic calculation. Metall. and Mater. Trans. A, 2016, 47(10), P. 4806-4817.

[15] Zaitsev A.I., Rodionova I.G., Pavlov A.A., Shaposhnikov N.G., Grishin A.V. Effect of composition, structural state, and manufacturing technology on service properties of high-strength low-carbon steel main bimetal layer. Metallurgist, 2015, 59(7), P. 684-692.

[16] Seto K., Funakawa Y., Kaneko S. Hot rolling high strength steels for suspension and chassis parts "NANOHITEN" and "BTH steels". JFE Techn. Report, 2007, 10, P. 19-25.

[17] Funakawa Y., Shiozaki T., Tomita K., Yamamoto T., Maeda E. Development of high strength hot-rolled sheet steel consisting of ferrite and nanometer-sized carbides. ISIJ Int., 2004, 44(11), P. 1945-1951.

[18] Deng X., Fu T., Wang Z., Liu G., Wang G., Misra R.D.K. Extending the boundaries of mechanical properties of Ti-Nb low-carbon steel via combination of ultrafast cooling and deformation during austenite-to-ferrite transformation. Met. Mater. Int., 2017, 23(1), P. 175-183. 
[19] Rijkenberg A., Blowey A., Bellina P., Wooffindin C. Advanced high stretch-flange formability steels for chassis \& suspension applications. Proceedings of the Conference SCT2014 (4-th International Conference on Steels in Cars and Trucks), Braunschweig, Germany, 15-19 June 2014, P. 426-433.

[20] Kosaka N., Funakawa Y. Work hardening in ferritic steel containing ultra-fine carbides. ISIJ Int., 2016, 56(2), P. 311-318.

[21] Zhang K., Li Z.-D., Sun X.-J., Yong Q.-L., Yang J.-W., Li Y.-M., Zhao P.-L. Development of Ti-V-Mo complex microalloyed hot-rolled 900-MPa-grade high-strength steel. Acta Metall. Sin. Engl., 2015, 28(5), P. 641-648.

[22] Wang Z., Sun X., Yang Z., Yong Q., Zhang C., Li Z., Weng Y. Carbide precipitation in austenite of a Ti-Mo-containing low-carbon steel during stress relaxation. Mater. Sci. Engin. A, 2013, 573, P. 84-91.

[23] Kim Y.W., Hong S-G., Huh Y-H, Lee C.S. Role of rolling temperature in the precipitation hardening characteristics of Ti-Mo microalloyed hot-rolled high strength steel. Mater. Sci. Engin. A, 2014, 615, P. 255-261.

[24] Bu F.Z., Wang X.M., Yang S.W., Shang C.J., Mirsa R.D.K. Contribution of interphase precipitation on yield strength in termomechanically simulated Ti-Nb and Ti-Nb-Mo microalloyed steels. Mater. Sci. Engin. A, 2015, 620, P. 22-29.

[25] Zajac S. Precipitation of microalloy carbo-nitrides prior, during and after $\gamma / \alpha$ transformation. Mater. Sci. Forum., 2005, 500, P. 75-86.

[26] Cheng L., Caai Q-W., Xie B-S., Ning Z., Zhou X-C., Li G-S. Relationships among microstroucture, precipitation and mechanical properties in different depths of Ti-Mo low carbon low alloy steel plate. Mater. Sci. Engin. A, 2016, 651, P. 185-191.

[27] Zaitsev A.I., Baklanova O.N., Koldaev A.V., Grishin A.V., Rodionova I.G., Yashchuk S.V., Lyasotskii I.V. Microstructure and property formation for high-strength low-carbon steels microalloyed with titanium and molybdenum. Metallurgist, 2016, 60(5), P. 492-498.

[28] Shaposhnikov N.G., Koldaev A.V., Zaitsev A.I., Rodionova I.G., D’yakonov D.L., Arutyunyan N.A. Regularities of titanium carbide precipitation in low carbon Ti-Mo-microalloyed high strength steels. Metallurgist, 2016, 60(8), P. 810-816.

[29] Wang Z., Yong Q., Sun X., Yang Z., Li Z., Zhang C., Weng Y. An analytical model for kinetics of stren-induced precipitation in titanium micro-alloyed steels. ISIJ Int., 2012, 52(9), P. 1661-1669.

[30] Koldaev A.V., D’yakonov D.L., Zaitsev A.I., Arutyunyan N.A. Kinetics of the formation of nanosize niobium carbonitride precipitates in low-alloy structural steels. Metallurgist, 2017, 60(9), P. 1032-1037. 